\title{
Manifestaciones oculares de la dermatitis atópica
}

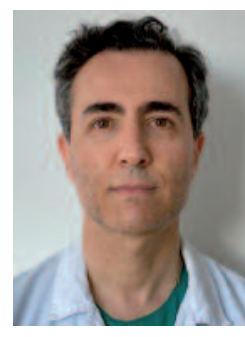

Constantino Jaime Reinoso Montalvo Médico adjunto. Servicio de Oftalmología. Hospital Universitario 12 de Octubre. Madrid.

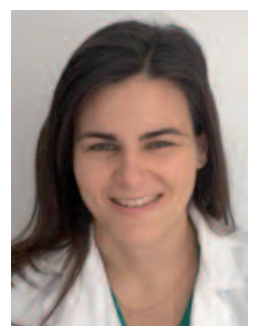

Mónica Gimeno Carrero

Médico interno residente. Servicio de Oftalmología. Hospital Universitario 12 de Octubre. Madrid.

\section{INTRODUCCIÓN}

La dermatitis atópica o eccema atópico es una enfermedad inflamatoria cutánea, de curso crónico y recidivante, que se caracteriza por piel seca, prurito y lesiones de morfología y distribución específicas, que se modifican a lo largo de la vida en un mismo paciente. Se podría definir también como la manifestación cutánea del síndrome atópico formado por la tríada de dermatitis, asma y rinitis.

En la dermatitis atópica, el prurito es el síntoma guía. El origen es multifactorial, de forma que los factores inmunitarios, genéticos y ambientales se relacionan entre sí, llevando a una alteración de la barrera cutánea y del microbioma cutáneo ${ }^{1}$, y a una regulación inmunitaria alterada. Se produce un trastorno que afecta a las células $\mathrm{CD} 4 \mathrm{~T}_{\mathrm{h}} 2$ (linfocitos $\mathrm{T}$ cooperadores de tipo 2), las cuales aumentan la producción de distintas interleucinas (IL) que producen inmunoglobulina $\mathrm{E}$ (IgE) frente a distintos alérgenos y proteínas.

La prevalencia en la población general es de un 5-20\%. En el $60 \%$ de los casos, el proceso se inicia en el primer año de vida —entre los 3 y 6 meses de edad-, y hasta en el $85 \%$, durante los 5 primeros años de vida. En la vida adulta, se encuentra una afectación del $3 \%$ de la población.

Un $20-40 \%$ de las personas afectadas por dermatitis atópica desarro- llará alteraciones oculares, principalmente, en forma de queratoconjuntivitis atópica ${ }^{2}$. La afectación ocular es, por lo tanto, un signo clínico de gran importancia, teniendo en cuenta, además, la intensa repercusión que puede producir en el estado psicológico y social del paciente.

\section{ANATOMÍA DEL SEGMENTO ANTERIOR OCULAR Y DE LOS ANEJOS}

En el segmento anterior ocular, se encuentran las siguientes estructuras anatómicas:

- Párpados: pliegues cutáneos móviles, superior e inferior, que intervienen en la protección ocular. En su espesor, se localizan numerosas estructuras que confieren al párpado una complejidad anatómica especial (músculos protectores y retractores, pestañas, y glándulas de Meibomio) (fig. 1). Es importante destacar que los párpados son la parte cutánea de menor espesor (de 0,6 a $2 \mathrm{~mm}$ ), esto es, la piel más fina del organismo, por lo que su absorción percutánea es especialmente intensa ${ }^{3}$.

- Conjuntiva: membrana mucosa transparente que recubre la superficie interna de los párpados (conjuntiva tarsal) y la superficie anterior ocular (conjuntiva bulbar) que termina en el limbo corneal. 


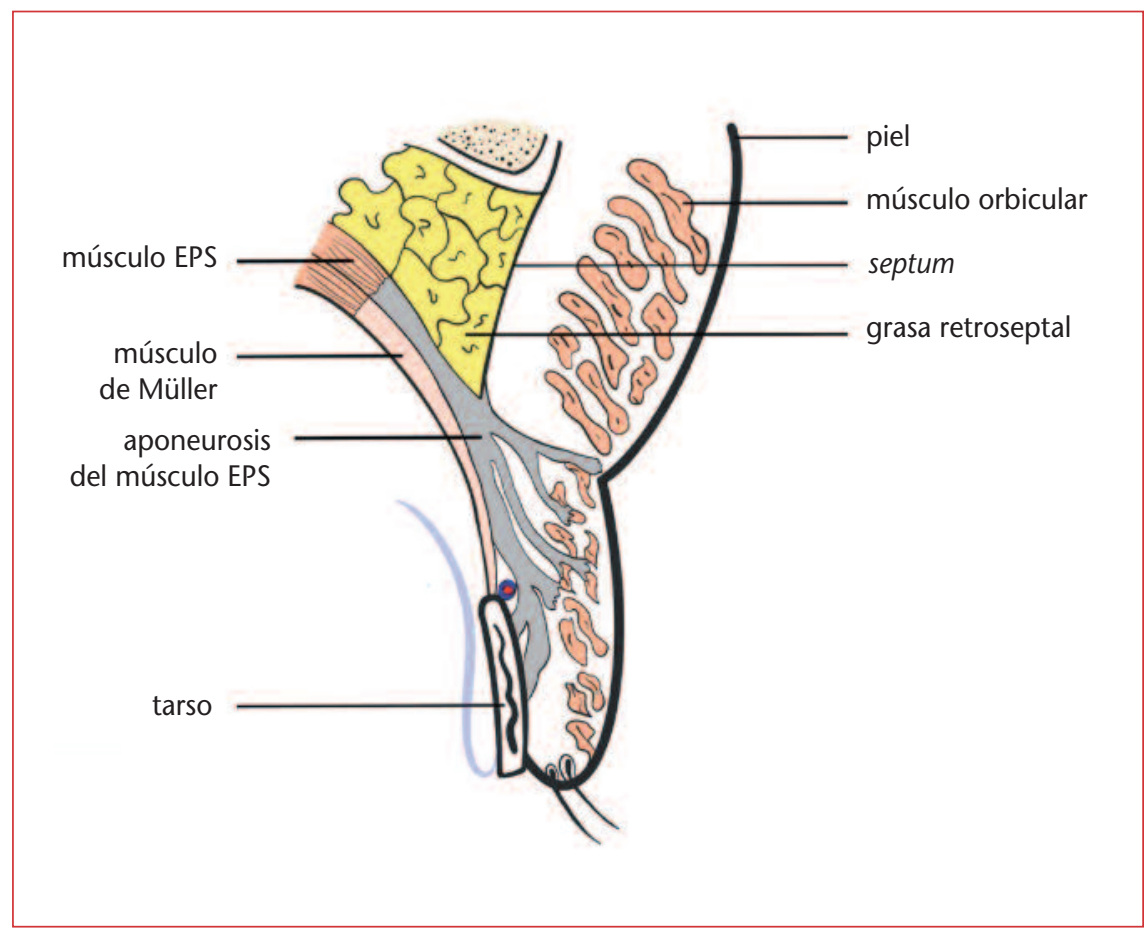

Figura 1. Esquema del párpado superior (cortesía de José María de la Cruz).

EPS: elevador del párpado superior.
- Córnea: estructura especializada de la esclera con unas características especiales. Tiene un papel protector ocular y es la responsable de, aproximadamente, tres cuartos del poder óptico del ojo. Es una estructura transparente, avascular y la estructura corporal más densamente inervada. Está constituida por cinco capas: epitelio corneal, membrana de Bowman, estroma corneal, membrana de Descemet y endotelio corneal.

- Cristalino: estructura transparente y biconvexa, situada en el interior del ojo, detrás del iris y delante del cuerpo vítreo. Actúa como una lente ocular. Es responsable de, aproximadamente, un cuarto del poder óptico del ojo y participa en el proceso de acomodación.

\section{ALTERACIONES OCULARES EN LA DERMATITIS ATÓPICA}

Las alteraciones oculares de la dermatitis atópica se resumen en la tabla 1.
El picor es el síntoma básico de esta enfermedad, y muchas alteraciones oculares están producidas por el rascado y el frotamiento de los párpados como consecuencia del picor.

\section{Blefaritis}

Es una enfermedad inflamatoria de los párpados. Puede verse afectada la parte más anterior del reborde palpebral (pestañas y piel) o la parte más posterior, con alteración de las glándulas de Meibomio. Su origen es multifactorial y suele asociarse a la queratoconjuntivitis atópica y a la queratoconjuntivitis vernal; también la blefaritis herpética es más frecuente en pacientes con dermatitis atópica ${ }^{4}$. Cursa con prurito, enrojecimiento palpebral y, con el tiempo, engrosamiento y xerosis de la piel del párpado. Un signo típico en el párpado inferior es el pliegue de Dennie-Morgan, que aparece durante los primeros meses de edad y que puede perdurar toda la vida. El rascado crónico puede afectar a las cejas, dando lugar al signo de Hertoghe, que consiste en la ausencia de 
Tabla 1. Alteraciones oculares en la dermatitis atópica

\begin{tabular}{l|c}
\hline Localización & Alteración \\
\hline Párpados & Blefaritis \\
\hline Córnea y conjuntiva & $\begin{array}{c}\text { Queratoconjuntivitis atópica } \\
\text { Queratocono } \\
\text { Queratitis por herpes }\end{array}$ \\
\hline Cristalino & Catarata \\
\hline Otras & Glaucoma, desprendimiento de retina \\
\hline
\end{tabular}

la parte lateral de las cejas secundaria al rascado crónico. El tratamiento se basa en tandas de calor seco de 5-10 minutos 2-3 veces al día y masaje palpebral para favorecer el drenaje de las glándulas obstruidas, lavados del borde palpebral con toallitas específicas o champús infantiles, emolientes cutáneos y, en algunas ocasiones, puede ser necesario el uso de corticoides tópicos de baja potencia o de ciclosporina oral.

\section{Queratoconjuntivitis atópica}

Es la inflamación no infecciosa de la córnea y la conjuntiva. Es más frecuente en adultos jóvenes, en torno a los 20-50 años de edad, y afecta a un porcentaje de entre el 25 y el $42 \%$ de los pacientes con dermatitis atópica ${ }^{5,6}$. Se manifiesta con secreción mucosa, picor, sensación de cuerpo extraño, hiperemia conjuntival (ojo rojo) y visión borrosa. Puede asociarse al eccema periocular. En la exploración física, podemos objetivar reacción conjuntival tarsal, quemosis (edema conjuntival), queratitis (lesiones corneales) en fases iniciales y simbléfaron (fusión de la conjuntiva bulbar con la tarsal, acortando los fondos de saco conjuntivales) en fases tardías. El diagnóstico diferencial incluye la conjuntivitis alérgica estacionaria por polen o perenne por ácaros y/o polvo, la conjuntivitis vernal (afecta a varones adolescentes, muchos de los cuales se harán atópicos) y la conjuntivitis papilar gigante en portadores de lentes de contacto. La afectación corneal puede provocar insuficiencia limbar con neovascularización y pérdi- da de la transparencia de la córnea, fotofobia y mala visión, y adelgazamiento y erosiones corneales de repetición. En los casos más graves, puede producirse un melting corneal, esto es, la licuefacción de la córnea, entidad de máxima gravedad, que, generalmente, necesita un trasplante. Con el objetivo de mejorar esta enfermedad, deben usarse lágrimas artificiales sin conservantes y sin vasoconstrictores. Del mismo modo, conviene añadir antihistamínicos tópicos como el ketotifeno tópico al $0,025 \%$ y estabilizadores de mastocitos como la olopatadina tópica al $0,1 \%$. Puede ser necesario añadir corticoides durante cortos períodos de tiempo, así como inhibidores de la calcineurina. Para controlar la inflamación a largo plazo, es preferible evitar los corticoides tópicos por el riesgo de aumento de la tensión ocular y usar, en su lugar, ciclosporina o tacrólimus tópico.

\section{Queratocono}

Es una ectasia corneal no inflamatoria de carácter progresivo. Está estrechamente asociado al frotamiento ocular debido al malestar que provoca la afectación ocular de la dermatitis atópica ${ }^{3,5,6}$. Se manifiesta en forma de visión borrosa con astigmatismo elevado. Su tratamiento es diverso dependiendo del estadio de la enfermedad e incluye el uso de lentes de contacto rígidas y anillos intraestromales corneales para corregir el astigmatismo. Si se pretende evitar la progresión, se puede recurrir al cross-linking del colágeno corneal que utiliza riboflavina e irradiación ultravioleta A (UVA), 
con el objeto de endurecer la córnea. En determinadas situaciones, puede ser necesaria la realización de un trasplante corneal.

\section{Catarata}

Aproximadamente el $10 \%$ de los pacientes con dermatitis atópica grave desarrolla cataratas entre la segunda y cuarta década de la vida ${ }^{5-7}$. Generalmente, son bilaterales y de desarrollo rápido. Hay varios tipos, siendo la catarata subcapsular anterior («en escudo») la que clásicamente se ha asociado a la dermatitis atópica. Se ha descrito relación con un nivel alto de IgE en sangre, así como con el traumatismo producido por el rascado ocular excesivo. Otro tipo de catarata que se asocia a la dermatitis atópica es la subcapsular posterior, estrechamente relacionada con el uso de corticoides, tanto tópicos como inhalados. El tratamiento de la catarata es quirúrgico.

\section{Glaucoma}

Es una neuropatía óptica progresiva, que puede provocar ceguera en estadios finales. Tiene origen multifactorial, siendo el factor de riesgo más importante y el único modificable la tensión ocular elevada. El uso crónico de corticoides eleva la tensión ocular, por lo que es recomendable que sean de baja potencia o utilizar ahorradores de corticoides como estabilizadores de mastocitos, ciclosporina e, incluso, inhibidores de las $\mathrm{IL}^{8}$. También se ha demostrado la existencia de un glaucoma intrínseco a la dermatitis atópica, que se caracteriza por un incremento de citocinas inflamatorias presentes en el humor acuoso (IL-8) y acumulación de fibras anormales en la malla trabecular ${ }^{8}$.

\section{Desprendimiento de retina}

Es una complicación muy grave, que puede presentarse en individuos jóvenes con dermatitis atópica, estimándose una incidencia en torno al 4-8\%. Su causa principal es el frotamiento ocular excesivo ${ }^{5,6}$. El tratamiento del desprendimiento de retina es quirúrgico (fig. 2).

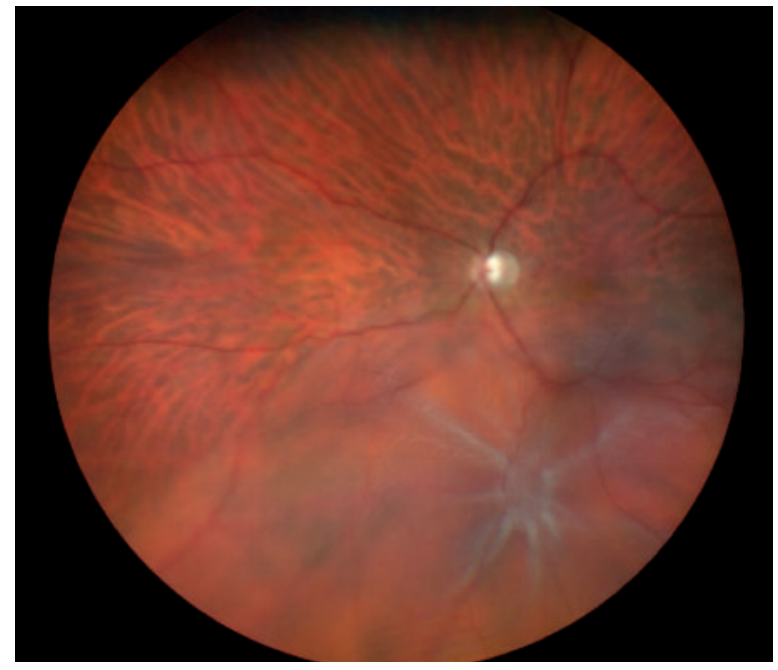

Figura 2. Desprendimiento de retina.

\section{Enfermedad ocular herpética}

Está causada por el virus del herpes simple 1 o 2. Suele presentarse en forma de ojo rojo doloroso. Está asociada a una notable morbilidad ocular, ya que las recurrencias pueden dar lugar a cicatrices corneales y pérdidas importantes de visión ${ }^{7}$. Los pacientes atópicos tienen una menor capacidad de regeneración del epitelio de la córnea, por lo que el riesgo de complicaciones visuales asociadas al herpes es mayor (fig. 3).

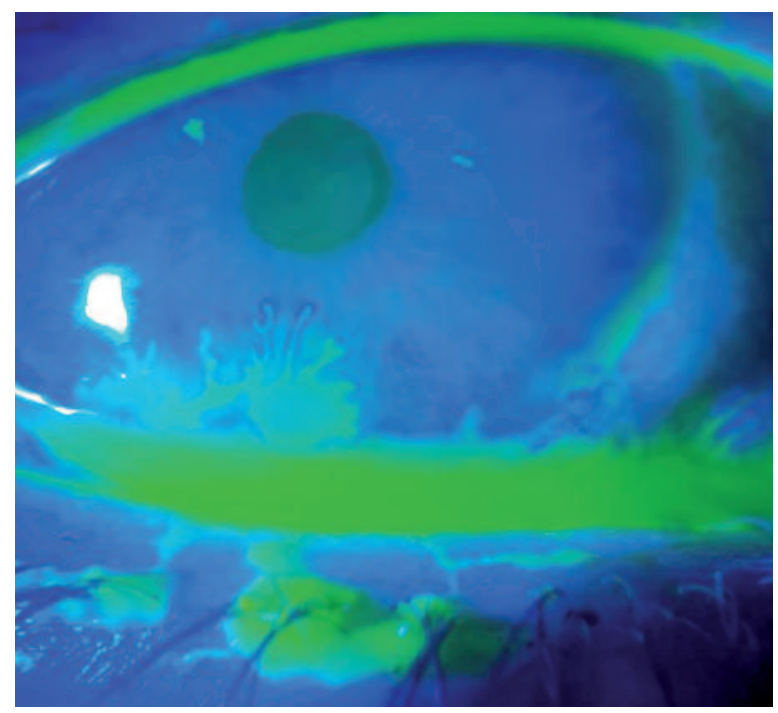

Figura 3. Dendrita herpética. 


\section{Complicaciones oculares asociadas al dupilumab}

El dupilumab, un anticuerpo monoclonal que bloquea la IL-4 y la IL-3, es el primer tratamiento biológico usado para la dermatitis atópica moderada y grave. Su principal efecto secundario es la conjuntivitis, que afecta al 5-28\% de los pacientes $^{9}$. Las manifestaciones clínicas incluyen hiperemia conjuntival y límbica, lagrimeo, sensación de quemazón ocular, así como disminución de la agudeza visual. El dupilumab también se ha asociado a la blefaritis. El tratamiento consiste en el uso de corticoides de baja potencia, como la fluorometolona oftálmica al 0,1\%, y del ungüento de tacrólimus al 0,03\%.

\section{CONCLUSIONES}

Los dermatólogos se encontrarán en la práctica clínica a muchos pacientes con dermatitis atópica y complicaciones oculares. Un diagnóstico precoz y el tratamiento de dichas complicaciones pueden prevenir la pérdida visual en este tipo de pacientes.
De igual manera, el conocimiento de los efectos secundarios del tratamiento de la dermatitis atópica, así como una relación fluida con el oftalmólogo reducirán de forma notable las complicaciones oculares.

\section{BIBLIOGRAFÍA}

1. Guerra-Tapia A, González-Guerra E. Prebióticos, probióticos, simbióticos y dermatitis atópica. Madrid: Editorial IMC; 2018.

2. Bielory B, Bielory L. Atopic dermatitis and keratoconjunctivitis. Immunol Allergy Clin North Am. 2010;30(3):323-36.

3. Guerra-Tapia, A. Estructura de la piel. En: Castelo Branco CA (ed.). Envejecimiento de la piel y las mucosas. Versión electrónica. Madrid: Editorial Médica Panamericana; 2015. p. 18.

4. Chen JJ, Applebaum DS, Sun GS, Pflugfelder SC. Atopic keratoconjunctivitis: a review. J Am Acad Dermatol. 2014;70(3): 569-75.

5. Beck KM, Seitzman GD, Yang EJ, Sanchez IM, Liao W. Ocular co-morbidities of atopic dermatitis. Part I: associated ocular diseases. Am I Clin Dermatol. 2019;20(6):797-805.

6. Beck KM, Seitzman GD, Yang EJ, Sanchez IM, Liao W. Ocular co-morbidities of atopic dermatitis. Part II: ocular disease secondary to treatments. Am J Clin Dermatol. 2019;20(6): 807-15.

7. Hsu Jl, Pflugfelder SC, Kim SJ. Ocular complications of atopic dermatitis. Cutis. 2019;104(3):189-93.

8. Garrott HM, Walland MJ. Glaucoma from topical corticosteroids to the eyelids. Clin Exp Ophthalmol. 2004;32(2):224-6.

9. Akinlade B, Guttman-Yassky E, De Bruin-Weller M, Simpson EL, Blauvelt A, Cork MJ, et al. Conjunctivitis in dupilumab clinical trials. Br J Dermatol. 2019;181(3):459-73. 